\title{
Morfologia e quantificação da microbiota intestinal do curimbatá (Prochilodus lineatus) e do cascudo cinza (Pterygoplichthys anisitsi) cultivados em cativeiro
}

\author{
[Morphology and quantification of intestinal microbiota of curimbatá (Prochilodus lineatus) and \\ the gray armored catfish (Pterygoplichthys anisitsi) reared in captivity] \\ L.C. Makino, F. Faustino, M.C.F. Paes, M.C. Beraldo-Massoli, M.V. Cardozo, \\ R.P. Schocken-Iturrino, L.S.O. Nakaghi
}

Faculdade de Ciências Agrárias e Veterinárias - UNESP - Jaboticabal, SP

\begin{abstract}
RESUMO
Todos os animais vivem em íntima associação com micro-organismos que desempenham importantes funções em seu desenvolvimento normal. Nos vertebrados, a mais populosa e complexa comunidade de micro-organismos reside no trato intestinal. O intuito do estudo foi quantificar, classificar e verificar morfologicamente a população microbiana intestinal de duas importantes espécies de peixes de água doce, o curimbatá (Prochilodus lineatus) e o cascudo cinza (Pterygoplichthys anisitsi). As amostras foram coletadas por meio de raspagens da mucosa intestinal, diluídas seriadamente até $10^{-4}$, semeadas em placas contendo ágar soja tripticaseína (TSA) e ágar chocolate (AC) para contagem de bactérias totais e identificação morfológica por Gram, em aerobiose e em anaerobiose facultativa, respectivamente. As contagens de bactérias totais mostraram resultados que variaram entre $10^{3}$ e $10^{4} \mathrm{ufc}_{\mathrm{fL}} \mathrm{mL}^{-1}$. Os tipos morfológicos encontrados foram cocos, leveduras e bastonetes Gram negativos e positivos. Estudos adicionais sobre os padrões de colonização microbiana e a morfologia dos micro-organismos aderidos à mucosa intestinal foram possíveis com o uso da microscopia eletrônica de varredura (MEV), sendo encontradas formas variadas de micro-organismos, tais como leveduras, formas cocoides e bacilares flageladas e não flageladas. A microbiota intestinal do curimbatá e a do cascudo cinza provaram ser bastante diversas e populosas, com o predomínio de micro-organismos Gram negativos.
\end{abstract}

Palavras-chave: microbiologia, peixe, intestino, morfologia

\begin{abstract}
All animals exist in intimate associations with microorganisms that play important roles in the hosts' normal development. In vertebrates, the most populous and complex community of microbes resides in the digestive tract. The aim of this research was to morphologically quantify, classify and verify the composition of intestinal microbiota of two species of freshwater fish, the Prochilodus lineatus and the Pterygoplichthys anisitsi. The samples were collected by scrapings of intestinal mucosa, serially diluted to $10^{-4}$, plated on tryptic soy agar (TSA) and chocolate agar (CA) for total bacterial counting and morphological identification by Gram, in aerobiosis and facultative anaerobiosis conditions, respectively. In the total bacterial counting results ranged between $10^{3}$ to $10^{4} \mathrm{cfu} . \mathrm{mL}^{-1}$. The morphological types found were cocci, yeasts and Gram negative and positive rods. Additional studies about patterns of microbial colonization and the morphology of the adhered microorganisms to the intestinal mucosa were possible using the scanning electron microscopy (SEM) and several forms of microorganisms, such as yeasts, cocci and bacillary shapes flagellated and non-flagellated were found. The intestinal microbiota of $\mathrm{P}$. lineatus and $\mathrm{P}$. anisitsi was diverse and populous, with a predominance of Gram negative microorganisms.
\end{abstract}

Keywords: microbiology, fish, gut, morphology

Recebido em 11 de agosto de 2010

Aceito em 22 de maio de 2012

E-mail: liliancrism02@yahoo.com.br 


\section{INTRODUÇÃ̃O}

Segundo Mansfield et al. (2010), nos animais terrestres a complexa comunidade microbiana do ambiente intestinal exerce importantes funções na digestão, na exclusão de patógenos e no desenvolvimento e maturação do sistema imune. As funções da microbiota intestinal dos peixes não se encontram tão bem estudadas como para humanos e outros animais homeotérmicos (Hovda et al., 2007).

Navarrete et al. (2010) afirmaram que, em peixes, mesmo a microbiota intestinal não sendo tão populosamente densa tal como nos animais terrestres e homeotérmicos, presume-se que ela desempenhe funções semelhantes na saúde e no crescimento do hospedeiro, pois em contraste com os animais terrestres os peixes possuem um estreito contato com a microbiota ambiental, devido ao habitat aquático (Silva et al., 2005).

A microbiota residente confere muitos benefícios para a fisiologia intestinal do hospedeiro, sendo, portanto, um exemplo real de relação simbiótica (Hooper e Gordon, 2001). Alguns destes benefícios incluem o metabolismo dos nutrientes e de substratos orgânicos e a contribuição para o fenômeno da resistência à colonização. Esta última é a capacidade da comunidade bacteriana do trato gastrointestinal de resistir à invasão do hospedeiro por micro-organismos estranhos (Bauer et al., 2006). Para a aquicultura, novas formulações dietárias utilizando componentes bacterianos como probióticos podem efetivamente combinar nutrição reforçada com profilaxia de doenças, ao diminuirem a carga bacteriana, seja por exclusão competitiva ou pela produção de substâncias inibidoras, podendo ainda estimular o sistema imunológico, além de produzirem enzimas digestivas suplementares (Verschuere et al., 2000).

Os peixes detritívoros desempenham importante papel nos ecossistemas onde vivem, atuando na fase de pré-mineralização da matéria orgânica presente no lodo, tornando-a mais facilmente degradável pelos micro-organismos ambientais, acelerando, dessa forma, a reciclagem de nutrientes (Lowe-MacConnel, 1999). Segundo Agostinho (1997), estes peixes podem atuar, ainda, na depuração de cursos d'água sujeitos à poluição orgânica, bem como no aumento da produção secundária dos mananciais.
O gênero Prochilodus é encontrado nos sistemas hidrológicos sul-americanos, e o Prochilodus lineatus é um teleósteo detritívoro que está amplamente distribuído nos rios do sudeste brasileiro. Alguns exemplares desta espécie podem atingir $75 \mathrm{~cm}$ de comprimento e $8,0 \mathrm{~kg}$ de peso (Godoy, 1975; Nachi et al., 1998). Sua ampla distribuição pelos rios brasileiros faz com que esta espécie constitua uma importante fonte de proteína animal para consumo humano (Galdiolli et al., 2002). Além disso, estes peixes contribuem para o equilíbrio do ecossistema fluvial, devido às características notáveis de sua biologia, como, por exemplo: (1) a produção de um grande número de descendentes por ciclo reprodutivo (Cemig/Cetec, 2000), os quais servem de alimento para outras espécies da cadeia alimentar; (2) seu hábito alimentar detritívoro os leva a não constituírem um competidor alimentar com as demais espécies mais exigentes nutricionalmente, fazendo com que sejam considerados como um consumidor primário na cadeia alimentar (Nachi et al., 1998).

O Pterygoplichthys anisitsi, conhecido também como cascudo cinza, é um loricariídeo de porte grande, com comprimento total e massa corpórea alcançando, aproximadamente, $50 \mathrm{~cm}$ e $900 \mathrm{~g}$, respectivamente (Weber, 1992; Cruz et al. 2009). É uma espécie com ocorrência na América do Sul, nas bacias do rios médio e alto Paraná, do Paraguai e do Uruguai (Langeani e Araújo, 1993; Cruz et al. 2009). O cascudo cinza é apreciado como alimento em algumas regiões do país, e os exemplares menores deste gênero são utilizados para fins ornamentais, conhecidos como "limpavidros", por se alimentarem do lodo que se acumula nas paredes do aquário (Cemig/Cetec, 2000). Por terem uma dieta detritívora (algas do perifíton e detritos), possuem os intestinos muito longos e enovelados, otimizando a digestão dos alimentos (Cemig/Cetec, 2000), podendo chegar a cerca de 15 vezes o comprimento do corpo (Nakatani et al., 2001).

Diante do exposto, $P$. lineatus e $P$. anisitsi foram escolhidos para este estudo devido às suas promissoras perspectivas para criação comercial e às limitadas informações sobre os componentes microbianos do ambiente intestinal quando esses peixes são criados em cativeiro. Sabe-se que alguns gêneros bacterianos, ao mesmo tempo em que podem estar relacionados à geração de enfermidades no próprio plantel, podem também 
causar doenças de veiculação alimentar aos consumidores humanos ou animais, gerando não somente um problema de sanidade aquícola, mas também de saúde pública, o que pode comprometer negativamente a sustentabilidade socioeconômica da atividade.

\section{MATERIAL E MÉTODOS}

A metodologia adotada para o desenvolvimento desta pesquisa foi aprovada pela Comissão de Ética e Bem-Estar Animal (CEBEA) da Universidade Estadual Paulista (UNESP), Jaboticabal-SP, sob o protocolo $\mathrm{n}^{\circ}$ 0016207-08.

No período de janeiro a abril de 2009, foram capturados 11 exemplares adultos de $P$. lineatus com comprimento total (CT) variando entre $39,8 \pm 1,42 \mathrm{~cm}$ e massa corporal (MC) com valores entre $1,007 \pm 0,11 \mathrm{~kg}$ e 11 espécimes adultos de $P$. anisitsi com CT de $36,1 \pm 4,07 \mathrm{~cm}$ e MC entre $0,350 \pm 0,12 \mathrm{~kg}$, provenientes dos viveiros do Centro de Aquicultura da Universidade Estadual Paulista (UNESP), Jaboticabal - SP, Brasil. Após a captura, os peixes foram mantidos em jejum alimentar por 24 horas em tanques de alvenaria de $1000 \mathrm{~L}$, providos com aeração constante e abastecimento contínuo de água.

As análises microbiológicas foram realizadas no Laboratório de Microbiologia do Departamento de Patologia Veterinária da UNESP, Jaboticabal, SP.

Os dados referentes às condições ambientais dos tanques foram aferidos nas datas das coletas. A temperatura da água, o oxigênio dissolvido e a saturação de oxigênio foram medidos em oxímetro digital (Modelo YSI 550 A), enquanto o $\mathrm{pH}$ e a condutividade $\mathrm{o}$ foram em condutivímetro digital multiparâmetro (Modelo YSI 63). A alcalinidade total e a concentração de amônia foram obtidas pelo método de Golterman et al. (1978).

Os peixes foram eutanasiados por prolongamento do plano anestésico, e o trato digestório removido assepticamente por meio de uma incisão longitudinal na cavidade celomática. $\mathrm{O}$ trato intestinal foi separado dos demais componentes do tubo digestivo e individualizado em três diferentes regiões: inicial, média e final. A delimitação das regiões intestinais foi baseada na localização anatômica topográfica do segmento, pela presença ou não de digesta e pelo aspecto morfológico das pregas da mucosa, seguindo a metodologia de Bértin (1958). As regiões intestinais foram abertas assepticamente e, quando necessário, enxaguadas com solução salina fisiológica estéril.

Para o cultivo microbiano, foram realizadas raspagens das mucosas das referidas regiões intestinais com swabs, que foram acondicionados em tubos de ensaio contendo solução salina fisiológica, sendo, então, submetidas a diluições seriadas na proporção de 1:10 na mesma solução até $10^{-4}$. Alíquotas de $1,0 \mathrm{~mL}$ de cada diluição das amostras foram semeadas pour plate em duplicata.

Para o crescimento microbiano foram utilizados dois meios de cultura: ágar soja tripticaseína (TSA) (TSA - Tryptic Soy Agar - Merck ${ }^{\circledR}$, Darmstadt, Alemanha) para incubação aeróbia e ágar chocolate (AC) (NA - Nutriente Agar Himedia $^{\circledR}$, Mumbai, Índia - acrescido com $7 \%$ de sangue ovino) para incubação em anaerobiose facultativa.

As placas semeadas em meio de AC foram acondicionadas em jarras de anaerobiose com atmosfera modificada constituída por: $10 \%$ de dióxido de carbono $\left(\mathrm{CO}_{2}\right), 80 \%$ de nitrogênio $\left(\mathrm{N}_{2}\right)$ e $10 \%$ de oxigênio $\left(\mathrm{O}_{2}\right)$ e incubadas por 48 - 72 horas em estufa a $25^{\circ} \mathrm{C}$. As placas semeadas em meio de TSA foram incubadas aerobicamente sob as mesmas condições por 24 -36 horas.

A leitura das placas foi realizada por meio de contagem das colônias e determinação das ufc. $\mathrm{mL}^{-1}$ (unidades formadoras de colônias) pela média aritmética das duplicatas. $\mathrm{Na}$ quantificação foram consideradas somente as placas que apresentaram entre 30 e 300 ufc. Os dados obtidos foram posteriormente analisados pelo programa estatístico SAS (Statistic Analysis System), versão 9.1. O delineamento estatístico foi realizado em blocos casualizados, considerando-se como tratamento as três regiões intestinais, e como blocos os dias das coletas. Os valores obtidos na contagem de bactérias intestinais totais foram submetidos à análise de variância a um nível de $5 \%$ de probabilidade. Nos casos em que houve diferença significativa, foi aplicado o teste de Tukey $(\alpha=5 \%)$. 
Foram selecionadas duas placas de cada diluição, sendo que em cada placa foram escolhidas ao acaso e individualizadas 30 colônias com morfologias variadas para identificação por Gram e também para que pudesse ser realizada uma estimativa sobre os tipos morfológicos de micro-organismos para cada região intestinal analisada. Para exprimir os resultados, foram feitos cálculos das frequências absolutas e relativas da ocorrência de cada tipo morfológico.

Para a análise morfológica da microbiota intestinal utilizando-se a MEV, dois peixes adultos de cada espécie foram submetidos a jejum alimentar durante 24 horas e eutanasiados da mesma maneira descrita para a microbiologia.

O tubo digestivo foi retirado e o trato intestinal separado dos demais componentes. Os intestinos foram individualizados em três diferentes regiões: inicial, média e final, seguindo-se as mesmas orientações da parte microbiológica. Fragmentos de cada região foram coletados, fixados em Karnovsky modificado (paraformaldeído 8\% + glutaraldeído $2,5 \%$ ) por 48 horas, lavados em tampão fosfato de sódio a $0,1 \mathrm{M}$ pH 7,4, pós-fixados em solução aquosa de tetróxido de ósmio a $1 \%$, lavados novamente em tampão e desidratados em série com concentrações crescentes de etanol. As amostras foram, então, submetidas ao secador de ponto crítico com $\mathrm{CO}_{2}$ líquido (Modelo BAL-
TEC), montadas em suportes de cobre, metalizadas com ouro (Modelo DENTON VACUM DESK III) e eletronmicrografadas em microscópio eletrônico de varredura (Modelo JEOL - JSM5410).

\section{RESULTADOS}

As variáveis físicas e químicas da água dos tanques de permanência dos peixes durante $\mathrm{o}$ período de jejum durante as amostragens foram: temperatura, oxigênio dissolvido, $\mathrm{pH}$, condutividade, alcalinidade total e amônia. Os valores obtidos foram, respectivamente: $22,19 \pm 1,88^{\circ} \mathrm{C}, 8,09 \pm 0,55 \mathrm{mg} / \mathrm{L}$, $8,55 \pm 0,24, \quad 171 \pm 22,01 \mu \mathrm{S}, 138,2 \pm 20,04 \mathrm{mg} / \mathrm{L}$ e $94,35 \pm 38,00 \mu \mathrm{g} / \mathrm{L}$

Os resultados quantitativos da população microbiana intestinal total das três regiões intestinais estudadas para $P$. lineatus e para $P$. anisitsi foram da ordem de $10^{3}$ e $10^{4}$ ufc. $\mathrm{mL}^{-1}$. Os dados referentes à contagem de bactérias intestinais totais obtidos para $P$. lineatus e para $P$. anisitsi estão apresentados na Tab. 1.

A Tab. 1 mostra que as contagens de bactérias intestinais totais (ufc. $\mathrm{mL}^{-1}$ ) nas regiões analisadas foram crescentes do início para o final do intestino para ambas as espécies de peixes estudadas, tanto em cultivos aeróbios (TSA) quanto em cultivos anaeróbios facultativos (AC).

Tabela 1. Contagem de bactérias totais aeróbias (TSA) e anaeróbias facultativas (AC) em ufc.mL $\mathrm{para}^{-1}$ $1,0 \mathrm{~mL}$ dos raspados de cada região intestinal analisada para P. lineatus e P. anisitsi

\begin{tabular}{cccccc}
\hline \multirow{2}{*}{ Espécie } & Meio & $\begin{array}{c}\text { Contagem } \\
\left(\text { ufc. } \mathrm{mL}^{-1}\right)\end{array}$ & & \multicolumn{3}{c}{ Região intestinal } \\
\cline { 4 - 5 } P. lineatus & & & Inicial (1)* & Média (2)* & Final (3)* \\
& & & & & \\
& TSA & ufc. mL $^{-1}$ & $10,94 \pm 0,19 \times 10^{3 \mathrm{C}}$ & $11,47 \pm 0,18 \times 10^{3 \mathrm{~B}}$ & $12,40 \pm 0,86 \times 10^{3 \mathrm{~A}}$ \\
& AC & ufc. $\mathrm{mL}^{-1}$ & $9,46 \pm 0,57 \times 10^{3 \mathrm{C}}$ & $9,84 \pm 0,50 \times 10^{3 \mathrm{~B}}$ & $10,45 \pm 0,47 \times 10^{3 \mathrm{~A}}$ \\
\hline P. anisitsi & & & & & \\
& TSA & ufc. $\mathrm{mL}^{-1}$ & $10,95 \pm 0,78 \times 10^{4 \mathrm{C}}$ & $11,54 \pm 0,78 \times 10^{4 \mathrm{~B}}$ & $13,47 \pm 0,85 \times 10^{4 \mathrm{~A}}$ \\
& AC & ufc. $\mathrm{mL}^{-1}$ & $9,29 \pm 0,73 \times 10^{3 \mathrm{C}}$ & $10,10 \pm 0,51 \times 10^{3 \mathrm{~B}}$ & $10,66 \pm 0,29 \times 10^{3 \mathrm{~A}}$ \\
\hline
\end{tabular}

*Média \pm Desvio-padrão. TSA: Tryptic Soy Agar. AC: ágar chocolate. As médias seguidas por letras maiúsculas nas linhas diferem entre si (Tukey, $\alpha=0,05)$.

Com relação aos tipos morfológicos de microorganismos encontrados nas três diferentes regiões intestinais para as duas espécies de peixes estudadas, nas placas incubadas em TSA cresceram cocos Gram positivos, leveduras e bastonetes Gram positivos e negativos. Já nas placas incubadas em AC, houve o crescimento de cocos Gram positivos e de bastonetes Gram positivos e negativos. 
As frequências absolutas e relativas de ocorrência destes micro-organismos nas três regiões intestinais analisadas para cada uma das espécies de peixes em estudo e para cada tipo de meio de cultura utilizado são apresentadas na Tab. 2.

Tabela 2. Frequência absoluta (fa) e relativa (fr) de ocorrência dos tipos morfológicos de micro-organismos identificados por Gram nas três regiões intestinais analisadas para $P$. lineatus e $P$. anisitsi

\begin{tabular}{|c|c|c|c|c|c|c|c|c|c|c|c|}
\hline \multirow[b]{3}{*}{ Espécie } & \multirow[b]{3}{*}{ Meio } & \multirow[b]{3}{*}{$\mathrm{N}$} & \multirow[b]{3}{*}{ Intestino } & \multicolumn{8}{|c|}{ Gram (+) ou (-) } \\
\hline & & & & \multicolumn{2}{|c|}{ Bacilos (+) } & \multicolumn{2}{|c|}{ Bacilos (-) } & \multicolumn{2}{|c|}{$\operatorname{Cocos}(+)$} & \multicolumn{2}{|c|}{ Leveduras (+) } \\
\hline & & & & $\mathrm{fa}(\mathrm{n})$ & fr $\%$ & $\mathrm{fa}(\mathrm{n})$ & $\mathrm{fr} \%$ & $\mathrm{fa}(\mathrm{n})$ & $\mathrm{fr} \%$ & $\mathrm{fa}(\mathrm{n})$ & $\mathrm{fr} \%$ \\
\hline \multirow{6}{*}{$\begin{array}{c}P . \\
\text { lineatus }\end{array}$} & \multirow{3}{*}{ TSA* } & 30 & Inicial & 11 & 36,7 & 13 & 43,3 & 6 & 20,0 & 0 & 0,0 \\
\hline & & 30 & Médio & 9 & 30,0 & 17 & 56,7 & 4 & 13,3 & 0 & 0,0 \\
\hline & & 30 & Final & 6 & 20,0 & 21 & 70,0 & 1 & 3,3 & 2 & 6,7 \\
\hline & \multirow{3}{*}{$\mathrm{AC}^{* *}$} & 30 & Inicial & 1 & 3,3 & 14 & 46,7 & 15 & 50,0 & 0 & 0,0 \\
\hline & & 30 & Médio & 0 & 0,0 & 27 & 90,0 & 3 & 10,0 & 0 & 0,0 \\
\hline & & 30 & Final & 4 & 13,3 & 12 & 40,0 & 14 & 46,7 & 0 & 0,0 \\
\hline \multirow{6}{*}{$\begin{array}{c}P . \\
\text { anisitsi }\end{array}$} & \multirow{3}{*}{ TSA* } & 30 & Inicial & 7 & 23,3 & 16 & 53,3 & 2 & 6,7 & 5 & 16,7 \\
\hline & & 30 & Médio & 4 & 13,3 & 17 & 56,7 & 5 & 16,7 & 4 & 13,3 \\
\hline & & 30 & Final & 3 & 10,0 & 24 & 80,0 & 3 & 10,0 & 0 & 0,0 \\
\hline & \multirow{3}{*}{$\mathrm{AC}^{* *}$} & 30 & Inicial & 4 & 13,3 & 23 & 76,7 & 3 & 10,0 & 0 & 0,0 \\
\hline & & 30 & Médio & 6 & 20,0 & 17 & 56,7 & 7 & 23,3 & 0 & 0,0 \\
\hline & & 30 & Final & 4 & 13,3 & 23 & 76,7 & 3 & 10,0 & 0 & 0,0 \\
\hline
\end{tabular}

*TSA: Tryptic Soy Agar. ** AC: ágar chocolate.

Observando-se a Tab. 2, nota-se a predominância da microbiota Gram negativa, tanto em aerobiose quanto em anaerobiose facultativa. A microbiota Gram positiva foi representada majoritariamente pelas formas cocoides e bacilares, seguidas pelas leveduras, que apresentaram uma frequência relativamente baixa de ocorrência frente aos demais micro-organismos.

Os bastonetes Gram positivos tiveram morfologias diversas, variando entre formas afiladas e alongadas, curtas e grossas, esporuladas ou não esporuladas. Com relação aos bastonetes Gram negativos, foram notadas formas alongadas e finas, curtas e grossas, sem esporos. Os cocos predominaram em arranjos triangulares (estafilococos) e lineares (estreptococos), sendo observadas também colônias de cocos isolados. As leveduras apresentaram suas formas típicas, ou seja, ovaladas e alongadas com formação de esporos arredondados.

Nas placas de cultivo anaeróbio facultativo em AC, uma considerável porcentagem das colônias de cocos Gram positivos (55\% para P. lineatus e $10 \%$ para $P$. anisitsi), de bastonetes Gram negativos $(20 \%$ para $P$. lineatus e $53 \%$ para $P$. anisitsi) e de bastonetes Gram positivos (21\% para $P$. anisitsi) formou ao seu redor halos de hemólise com diâmetros variáveis, sendo este um fenômeno indicativo de fundamental relevância nos processos patogênicos nos hospedeiros, que tanto podem ser o próprio plantel de peixes como os consumidores deste pescado.

As eletronmicrografias de varredura mostraram os diferentes tipos morfológicos de microorganismos aderidos à superfície mucosa e os padrões de colonização das regiões intestinais analisadas para as duas espécies de peixes. Tanto para $P$. lineatus quanto para $P$. anisitsi, as eletronmicrografias de varredura da superfície mucosa das regiões intestinais estudadas mostraram a presença predominante das formas cocoides e de leveduras, constando também as formas bacilares, flageladas ou não.

Alguns exemplares dos diferentes morfotipos de micro-organismos encontrados em cada uma das regiões intestinais de $P$. lineatus analisadas podem ser vistas na Fig. 1: A, B, C, D, E e F. Nas eletronmicrografias de varredura A e B, que representaram a região intestinal inicial, houve a predominância das formas cocoides e leveduriformes. Na região intestinal média, as eletronmicrografias $\mathrm{C}$ e $\mathrm{D}$, além das formas cocoides e leveduriformes, mostraram também formas bacilares não flageladas esparsas. $\mathrm{Na}$ região intestinal final, nas eletronmicrografias $\mathrm{E}$ e F, destacaram-se as formas bacilares flageladas unipolares, dentre outros morfotipos já citados. 

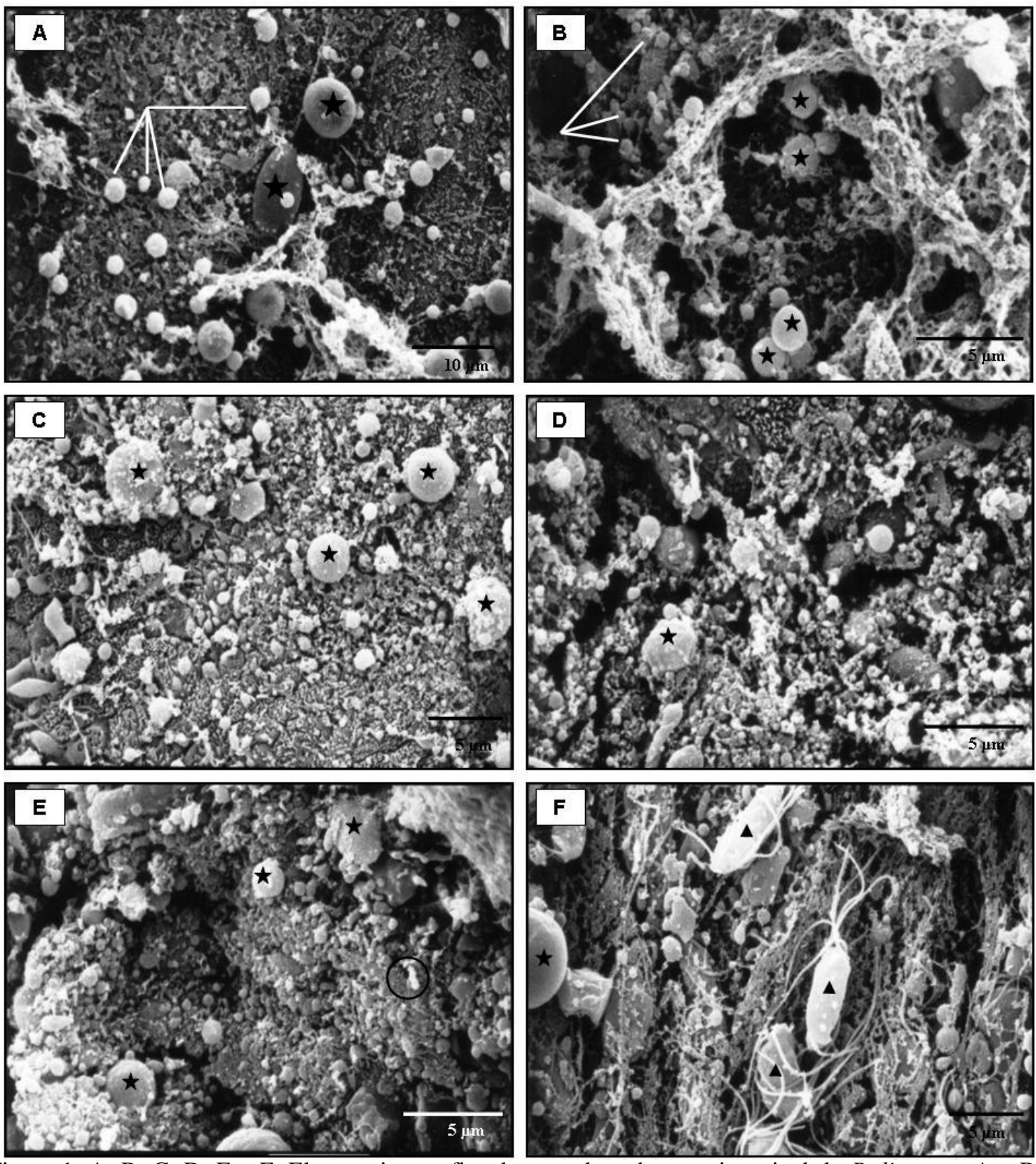

Figura 1. A, B, C, D, E e F. Eletronmicrografias de varredura do trato intestinal de $P$. lineatus. A e B. Região inicial: leveduras (estrelas) e formas cocoides (linhas). C e D. Região média: formas cocoides e bacilares esparsas e de leveduras (estrelas). E e F. Região final: leveduras (estrelas), formas cocoides esparsas e elementos bacilares não flagelados (círculo) e flagelados (ponta de seta).

Para P. anisitsi, a Fig. 2: A, B, C, D, E e F mostrou as diferentes morfologias dos microorganismos encontrados nas regiões intestinais estudadas. As eletronmicrografias mostraram basicamente a ocorrência das formas cocoides e leveduriformes, para as três regiões intestinais analisadas. 

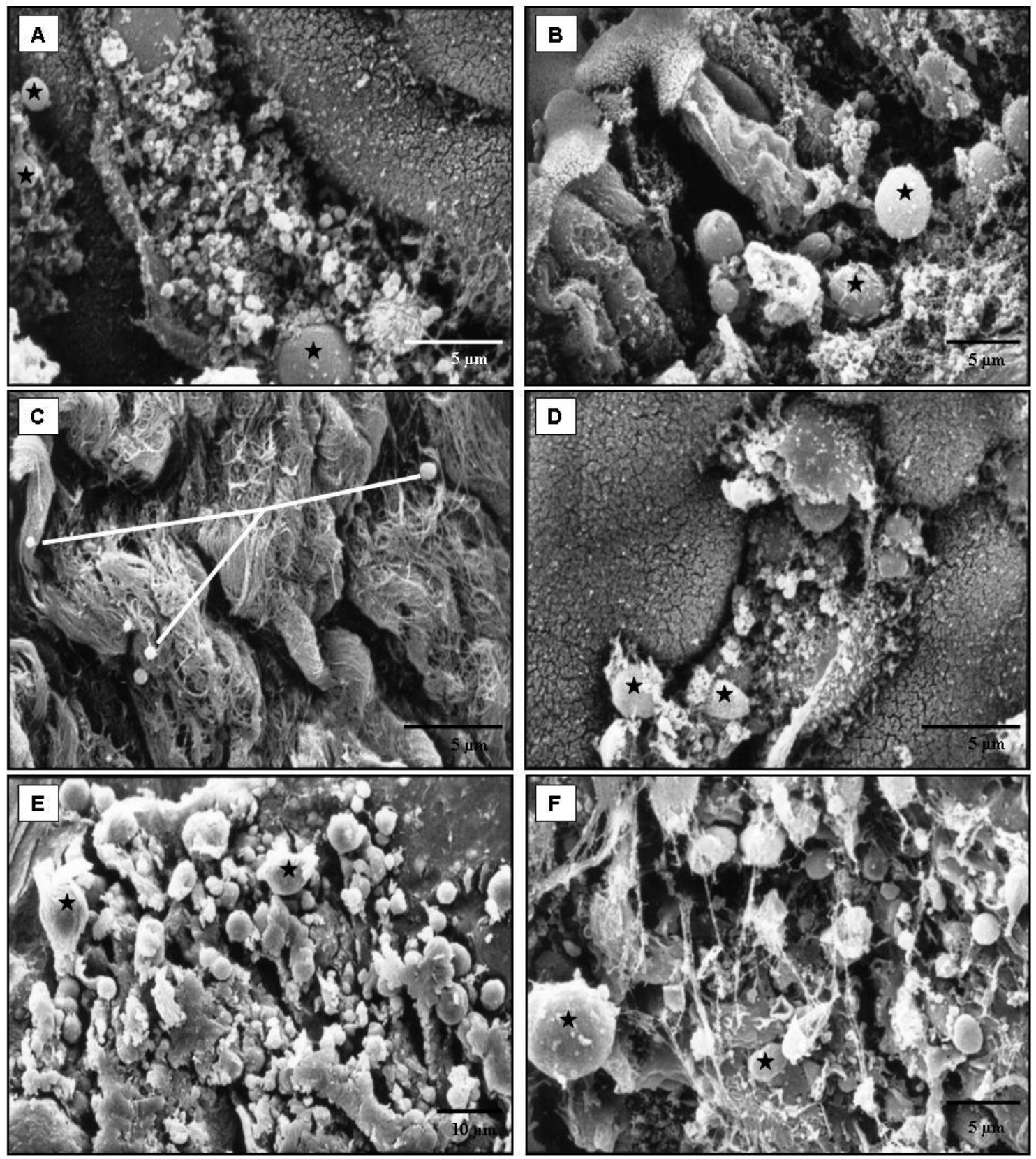

Figura 2. A, B, C, D, E e F. Eletronmicrografias de varredura do trato intestinal de P. anisitsi. A e B. Região inicial: leveduras (estrelas) e formas cocoides esparsas. C e D. Região média: elementos cocoides (linhas) e leveduras (estrelas). E e F. Região final: leveduras (estrelas), formas cocoides e de elementos bacilares.

\section{DISCUSSÃO}

Os dados obtidos que denotaram a qualidade hídrica dos tanques de permanência dos peixes durante o período de jejum encontraram-se inclusos nos valores compatíveis com a sobrevivência de organismos aquáticos, incluindo peixes (Boyd, 1990 e Sipaúba-Tavares, 1995).

As populações de micro-organismos foram crescentes do início ao final do intestino, sendo que as maiores concentrações destes foram encontradas nas amostras obtidas das regiões 
intestinais finais para ambas as espécies, independentemente dos meios de cultura e das condições de incubação. Os resultados da contagem da população microbiana intestinal total foram da ordem de $10^{3}$ e $10^{4}$ ufc. $\mathrm{mL}^{-1}$. Nos trabalhos de Silva et al. (2005) e de Lima et al. (2006), as contagens encontradas foram da ordem de $10^{6}$ e $10^{5}$, respectivamente. As contagens de bactérias intestinais totais no trabalho de Al-Harbi e Uddin (2005) atingiram valores entre $10^{7}$ e $10^{8}$. Contudo, nestes estudos foram coletadas amostras do conteúdo intestinal utilizando-se a maceração das alças intestinais como um todo e não apenas do material obtido de raspados da mucosa, fato que poderia mascarar a quantificação de bactérias autóctones aderentes pela contaminação por microorganismos transientes ou alóctones.

Contagens globais realizadas em diferentes regiões intestinais (intestino inicial, médio e final) por Olsen et al. (2005) e Refstie et al. (2006) revelaram contagens da ordem de $10^{4} \mathrm{e}$ $10^{3}$ para bactérias autóctones aderentes, fato que corroborou os dados obtidos neste trabalho. Neste caso, seria de relevante importância lembrar que condições de estresse (Olsen et al., 2005), estágio reprodutivo (Silva et al., 2005), idade (Bates et al., 2006), mudanças abruptas na dieta bem como a adição de certos componentes nesta exerceram influências muitas vezes negativas sobre a densidade populacional na microbiota intestinal, com alterações também nos gêneros dos micro-organismos componentes dela (Ringo e Olsen, 1999; Ringo et al., 2002; Refstie et al., 2006).

No entanto, o intuito da presente pesquisa foi apenas realizar uma checagem dos níveis populacionais e também qualificar os componentes da microbiota intestinal dos peixes em condições normais de criação em viveiros escavados, sem testar os efeitos de novas dietas ou de ingredientes específicos ou, ainda, de medicamentos sobre a composição da microbiota intestinal.

Em contraste com os vertebrados terrestres, os peixes apresentam um contato muito estreito com a microbiota ambiental devido ao ambiente aquático e ao fato de os micro-organismos presentes na água influenciarem a microbiota do intestino do hospedeiro e vice-versa (Silva et al., 2005; Meurer et al., 2006). Segundo
Toranzo et al. (1989), as bactérias mais bem adaptadas à vida no solo e água pertencem aos gêneros Bacillus e Pseudomonas, microorganismos bacilares aeróbios Gram positivos e Gram negativos, respectivamente. Porém, outros grupos podem estar presentes em água doce, incluindo membros da família Enterobacteriaceae e gêneros como Flavobacterium, Acinetobacter, Moraxella, Aeromonas, que são bacilos Gram negativos, podendo conter também os micro-organismos cocoides e Gram positivos, tais como os gêneros Micrococcus, Staphylococcus e Streptococcus. Dentre estas famílias e gêneros, há bactérias com potencial patogênico variável, sendo que, em culturas com ágar sangue, estas formaram halos de hemólise, fato que corroborou os resultados obtidos nas placas cultivadas em ágar chocolate, indicando a presença de bactérias patogênicas, já que se formaram halos de hemólise com diferentes diâmetros.

No presente trabalho, de uma maneira geral, foram identificados pela técnica de Gram microorganismos Gram positivos, que se coraram em roxo-azulado, e Gram negativos, que assumiram a coloração vermelho-rósea. Os morfotipos encontrados foram cocos, leveduras e bastonetes. $\mathrm{Na}$ categoria dos micro-organismos Gram positivos, estiveram locados os elementos cocoides, bacilares e as leveduras. Silva et al. (2005) relataram a ocorrência de leveduras com frequência relativamente baixa no intestino de Prochilodus argenteus, fato que corroborou os dados encontrados neste estudo. No entanto, segundo Gatesoupe (2007), algumas substâncias extraídas de leveduras, como, por exemplo, as $\beta$-glucanas, podem ser usadas como imunoestimulantes, e, mais recentemente, leveduras vivas podem ser usadas como probióticos, podendo ter implicações significativas na saúde dos peixes. $\mathrm{Na}$ presente pesquisa, as formas bacilares destacaram-se no grupo das bactérias Gram negativas. O perfil da microbiota em pisciculturas de água doce é predominantemente constituído por bactérias Gram negativas. Miranda e Zemelman (2002), ao avaliarem a diversidade da microbiota bacteriana em diferentes fazendas chilenas de salmão de água doce, constataram que a microbiota predominante das fazendas foi constituída por bactérias Gram negativas. 
A adesão bacteriana é um fenômeno de interação célula-superficie, e esta propriedade a faz ideal para as análises em MEV (Knutton, 1995; Ringo et al., 2003). A MEV apresenta a vantagem, ao contrário da microscopia eletrônica de transmissão, de possibilitar o exame mais rápido das bactérias aderentes colonizadoras e de áreas mais extensas da superfície celular (Ringo et al., 2003).

As eletronmicrografias de varredura mostraram a diversidade dos micro-organismos encontrados na superfície da mucosa das diferentes regiões intestinais analisadas. Nestas, foram encontrados com maior frequência micro-organismos cocoides e leveduriformes. A predominante presença de bactérias cocoides também foi relatada no trabalho de Ringo e Olsen (1999) e Ringo et al. (2002). Austin e Al-Zahrani (1988) relataram dificuldades na detecção da presença de leveduras e fungos pela MEV no trato gastrointestinal de peixes. No entanto, nesta pesquisa, as leveduras foram detectadas com relativa facilidade em MEV, sendo inclusive predominantes nas regiões intestinais iniciais.

Com relação às formas bacilares flageladas unipolares encontradas nas regiões intestinais finais do $P$. lineatus, estas podem bem corresponder às bactérias do gênero Aeromonas spp., visto ser este gênero predominante em ambientes de água doce e na microbiota de peixes, cuja morfologia apresenta flagelos unipolares, conferindo-lhes motilidade (Boijink e Brandão, 2001; Ringo et al., 2002). No entanto, como mencionado anteriormente, estudos e testes adicionais serão necessários para comprovação dos gêneros destes micro-organismos.

\section{CONCLUSÃO}

Diante dos resultados, concluiu-se que a microbiota intestinal do $P$. lineatus e a do $P$. anisitsi nos termos morfológicos e quantitativos mostraram ser bastante diversas e populosas, predominando a microbiota Gram negativa.

\section{AGRADECIMENTOS}

À Fundunesp, pelo auxílio financeiro, e ao CNPq, pela bolsa de estudo;.ao Dr. Rúben Pablo Schocken-Iturrino, à Sra. Sivina do Carmo Pelicano Berchielli, pelos suportes técnico e logístico durante a pesquisa, e à Cláudia
Aparecida Rodrigues, pela colaboração nas eletronmicrografias de varredura.

\section{REFERÊNCIAS}

AGOSTINHO, A.A.; HANH, N.S.; GOMES. L.C. et al. Estrutura trófica. In: VAZZOLER, A.E.A.A.M.; AGOSTINHO, A.A.; HAHN, N.S. (editores). A planície de inundação do Rio Paraná: aspectos físicos, biológicos e socioeconômicos. Maringá: EDUEM/NUPELIA, 1997, p. 229-248.

AL-HARBI, A.H.; UDDIN, N. Bacterial diversity of tilapia (Oreochromis niloticus) cultured in brackish water in Saudi Arabia. Aquaculture, v.250, p.566-572, 2005.

AUSTIN, A.; AL-ZAHRANI, A.M.J. The effect of antimicrobial compounds on the gastrointestinal microflora of rainbow trout, Salmo gairdneri Richardson. J. Fish Biol., v.33, p.1-14, 1988.

BATES, J.M.; MITTGE, E.; KUHLMAN, J. et al. Distinct signals from the microbiota promote different aspects of zebrafish gut differentiation. Develop. Biol., v.297, p.374-386, 2006.

BAUER, E.; WILLIAMS, B.A.; SMIDT, H. et al. Influence of the gastrointestinal microbiota on development of the immune system in young animals. Curr. Iss. Int. Microbiol., v.7, p.35-52, 2006.

BÉRTIN, L. Appareil digestif. In: Traité de zoologie, anatomie, systématique, biologie. Paris: Masson,1958. p.1249-1300.

BOIJINK, C.L.; BRANDÃO, D.A. Inoculação bacteriana de Aeromonas hidrophyla e a sobrevivência de juvenis de jundiá, Rhamdia quelen (Teleostei: Pimelodidae). Cienc. Rural, v.31, p.503-507, 2001.

BOYD, C.E. Water quality in ponds for aquaculture. Auburn: Auburn University Press/Birmingham publishing Co. Alabama. 1990. 482p.

CEMIG (Companhia Energética de Minas Gerais). Guia ilustrado de peixes da bacia do Rio Grande. Fundação Centro Tecnológico de Minas Gerais, CEMIG/CETEC, Belo Horizonte, 2000. $144 p$. 
CRUZ, A.L.; PEDRETTI, A.C.E.; FERNANDES, M.N. Stereological estimation of the surface area and oxygen diffusing capacity of the respiratory stomach of the atir-breathing armored catfish Pterygoplichthys anisitsi (Teleostei: Loricariidae). J. Morphol., v.270, p.601-614, 2009.

GALDIOLI, E.M.; HAYASHI, C.; SOARES, C.M. et al. Substituição da proteína do farelo de soja pela proteína do farelo de canola em rações para alevinos de curimbatá (Prochilodus lineatus V.). Rev. Bras. Zootec., v.31, p.552-559, 2002.

GATESOUPE, F.J. Live yeasts in the gut: natural occurrence, dietary introduction, and their effects on fish health and development. Aquaculture, v.267, p.20-30, 2007.

GODOY, M.P. Peixes do Brasil. Subordem Characoidei. Bacia do Rio Mogi-Guassu. São Paulo: Editora Franciscana, 1975. 847p.

GOLTERMANN, H.L.; CLYMO, R.S.; OHNSTAD, M.A.M. Methods for physical and chemical analisis of freshwaters. London: Blackwell Science Publication, 1978. 214p.

HOOPER, L.V.; GORDON, J.I. Commensal hostbacterial relantionships in the gut. Science., v.292, p.1115-1118, 2001.

HOVDA, M.B.; BJORN, T.L.; FONTANILLAS, R. et al. Molecular characterization of the intestinal microbiota of farmed Atlantic salmon (Salmon salar L.). Aquaculture, v.272, p.581588, 2007.

KNUTTON, S. Electron microscopical methods in adhesion. Meth. Enzymol., v.253, p.145-158, 1995.

LANGEANI, F.; ARAÚJO, R.B. Liposarcus weberi sp. n., um novo Loricariidae (Ostariophysi, Siluriformes) da bacia do Alto Paraná, Brasil. In: Projeto Cascudo, Instituto de Biociências, Letras e Ciências Exatas, Universidade Estadual Paulista, São José do Rio Preto - SP, 1993.

LIMA, R.M.S.; FIGUEIREDO, H.C.P.; FARIA, F.C. et al. Resistência a antimicrobianos de bactérias oriundas de ambiente de criação e filés de tilápias do Nilo (Oreochromis niloticus). Cienc. Agrotec., v.30, p.126-132, 2006.
LOWE-MAcCONNEL, R.H. Estudos ecológicos de comunidades de peixes tropicais. Tradução de Anna Emília A.M. Vazzoler; Ângelo Antônio Agostinho; Patrícia T.M. Cunningham. São Paulo: EDUSP, 1999. 535p. Título original: Ecological studies in tropical fish communities.

MANSFIELD, G.S.; DESAI, A.R.; NILSON, S.A. et al. Characterization of rainbow trout (Onchorhynchus mykiss) intestinal microbiota and inflammatory marker gene expression in recirculating aquaculture system. Aquaculture, v.307, p.95-104, 2010.

MEURER, F.; HAYASHI, C.; COSTA, M.M. et al. Utilização de Saccharomyces cerevisiae como probiótico para tilápias-do-nilo durante o período de reversão sexual submetidas a um desafio sanitário. Rev. Bras. Zootec., v.35, p.1881-1886, 2006.

MIRANDA, C.D.; ZEMELMAN, R. Antimicrobial multiresistance in bacteria isolated from freshwater Chilean salmon farms. Sci. Tot. Environ., v.293, p.207-218, 2002.

NACHI, A.M.; BLASQUEZ, F.J.H.; BARBIERI, R.L. et al. Intestinal histology of a detritivorous (iliophagous) fish Prochilodus scrofa (characiformes, prochilodontidae). Ann. Sci. Nat., v.2, p.81-88, 1998.

NAKATANI, K.; AGOSTINHO, A.A.; BAUMGARTNER, G. et al. Ovos e larvas de peixes de água doce: Desenvolvimento e manual de identificação. 1.ed. Maringá: UEM (Universidade Estadual de Maringá), 2001. 378p.

NAVARRETE, P.; MAGNE, F.; MARDONES, P. et al. Molecular analysis of intestinal microbiota of rainbow trout (Oncorhynchus mykiss). FEMS Microb. Ecol., v.71, p.148-156, 2010.

OLSEN. R.E.; SUNDELL, C.; MAYHEW, T.M. et al. Acute stress alters intestinal functions of rainbow trout, Orcorhynchus mykiss (Walbaum). Aquaculture, v.250, p.480-495, 2005.

REFSTIE, S.; LANDSVERK, T.; McKELLEP, A.M.B. et al. Digestive capacity, intestinal morphology, and microflora of 1 - year and 2 year old Atlantic Cod (Gadus morhua) fed standard or bioprocessed soybean meal. Aquaculture, v.261, p.829-841, 2006. 
RINGO, E.; LODEMEL, J.B.; MYKLEBUST, R. et al. The effects of soybean, linseed and marine oils on aerobic gut microbiota of Arctic charr Salvelinus alpinus L. before and after challenge with Aeromonas salmonicida ssp. salmonicida. Aquacult. Res., v.33, p.591-606, 2002.

RINGO, E.; OLSEN, R.E. The effect of diet on aerobic bacterial flora associated with intestine of Arctic charr (Salvelinus alpinus L.). J. Appl. Microbiol., v.86, p.22-28, 1999.

RINGO, E.; OLSEN, R.E.; MAYHEW, T.M. et al. Electron microscopy of the intestinal microflora of fish. Aquaculture, v.227, p.395415, 2003.

STATISTIC Analysis System (SAS) version 9.1. SAS Institute, Cary, North Carolina - user's guide, 2007

SILVA, F.C.P.; BRITO, M.F.G.; FARIAS, L.M. et al. Composition and antagonistic activity of the indigenous intestinal microbiota of Prochilodus argenteus Agassiz. J. Fish Biol., v.67, p.1686-1698, 2005.

SIPAÚBA-TAVARES, L.H. Variações Hidrológicas (Capítulo 4).. In: Sipaúba-Tavares, L.H. Limnologia aplicada à aquicultura. Boletim Técnico do CAUNESP. $\mathrm{n}^{\mathrm{o}}$ 1. Jaboticabal: FUNEP, 1995. p.27-34

TORANZO, A.E.; BAYA, A.M.; ROMALDE, J.L. et al. Association of Aeromonas sobria with mortalities of adult gizzard shad, Dorosoma cepedianum Leseur. J. Fish Dis., v.12, p.439448, 1989.

VERSCHUERE, L.; ROMBAUT, G.; SORGELOOS, P. et al. Probiotic bacteria as biological control agents in aquaculture. Microbiol. Molec. Biol. Rev., v.64, p.655-671, 2000.

WEBER, C. Révision du genre Pterygoplichhys sensu lato (Pisces, Siluriformes, Loricariidae). Rev. Française d'Aquariol., v.10, p.1-36, 1992. 